\title{
A Critical Analysis on Confucian Sexism Through the Lens of Care Ethics: A Case of Domestic Labor Division
}

\author{
Bo Zhang ${ }^{1}$
}

\author{
${ }^{1}$ Faculty of Arts and Philosophy, Vrije Universiteit Brussel, Brussels 1050, Belgium.
}

\begin{abstract}
According to three nationwide surveys on the status of Chinese women carried out in 1990,2000, and 2010 respectively, the unfair gendered division of domestic care labor is a chronic problem in China. Scholars regard the sexist thoughts in Confucianism as an endogenous element leading to this inequality. Some comparisons between Confucianism and feminist ethics of care have begun emerging in recent years because of their common concerns of "care." However, one of the striking features of feminist care ethics is their reflections on patriarchy, which distances themselves from Confucianism. This paper investigates whether and how the ethics of care's criticism on the masculine dominance could shed light on the ongoing problem of gender-based division of domestic caring responsibility in China. This paper starts from an overview of the ethics of care, mainly referred to Joan Tronto's care theories, to explore how their arguments rescue care from the dangers of patriarchy and hierarchy. Then, this paper tries to reflect on Confucianism via the lens of the ethics of care in the case of domestic labor division, based on carefully scrutinizing the sexist notions in Confucianism. In the conclusion, this paper discusses the potential enlightenments stemming from care ethics to bail Confucianism out of the malady of gendered care.
\end{abstract}

Keywords: care ethics, moral boundaries, Confucianism, gendered division of domestic labor

\section{INTRODUCTION}

Scholars report on an ongoing gap between the commitment of care labor in family undertaken by women on the one hand and the men on the other. One of the democratic tasks for the ethics of care is to close this gap by breaking up the moral boundary between private and public domains, and by interpreting care in a de-gendered lens supplied by national support. These observations from the ethics of care are highly promising to shed light on analysing the status quo of unequal division of domestic labor in China, whose endogenous cultural reason stems from the remaining sexist thoughts in Confucianism [1]. In the first part of this paper, I elaborate on the reflections from the ethics of care as the basis of following critical analysis, including its challenge to the moral boundaries between the public and private, as well as its criticism on the undervaluation and gendered construction of care labor. Subsequently, I illustrate the actuality of unbalanced division of care work in Chinese families by analysing the data from national surveys. I specifically clarify the gender boundaries in Confucianism embodied in of Yin(feminine)-Yang(masculine) and Nei(domestic)Wai(public) systems to investigate to what extent the Confucianist ceremonies expose women to the overcommitment of care labor in the critical perspective of care ethics. In the final part, I discuss the necessary of getting rid of the gender stereotypes in Confucianism and try to figure out strategies to rescue women from the overburden of care labor.

\section{BACKGROUND}

In recent decades, a lively debate has been developed around the question of whether the Confucian ethics share adequate similarities with the ethics of care to warrant the claim that Confucian ethics resemble care ethics. Various authors have answered this question differently, for example, Chenyang Li argues that "Jen" in Confucianism, which is a vitally central term in Confucianism, is similar to the concept "care" in the ethics of care. Besides, the conventional viewpoint women were inferior to men is not necessarily intrinsic to Confucian thoughts [2]; while other scholars, such as Lijun Yuan, reject this hypothesis because the ethics of care is a kind of new and fastdeveloping philosophy that is regarded as inherently antipatriarchal. Confucianism, on the contrary, is an established traditional philosophy that has been regarded as typically patriarchal [3]. In addition, R.S. Herr points out that western conceptions of family no matter from the justice perspective or care ethics may be neither plausible nor feasible in traditionally Confucian societies. Nevertheless, he suggests a harmonious and feminist family can be constructed in East Asian context according to the original Confucianist ideas [4]. As far as I am concerned, it cannot be denied that these two theoretical systems share an identical emphasis on the importance of care both in societal and domestic domains, which acts as 
the foundation of cultivating morality and regulating daily routines. Even so, after evaluating the Confucian understanding on the relationship between care and gender in the lens of care ethics, sustaining their resemblance is nearly impossible. Also, it is difficult for Confucianism to escape from the blame of sexism, especially in the case of gendered labor division, whose influence still remains in contemporary China. Thus, it would be meaningful to suspend the disputes on the relationship between care ethics and Confucianism temporarily and focus on the arguments of care ethics concerning the challenge to the moral boundary between private and public spheres as well as its theoretical construction of de-gendered care, which could enlighten the Confucianism to overcome its malady of sexism.

\section{THE ETHICS OF CARE: CHALLENGE AND RECONSTRUCTION}

\subsection{Challenge to the Moral Boundary of Private and Public Spheres}

Feminist scholars have long noted that, while the particular line drawn between public and private life changes over time and with varying cultural circumstances, there is a split between public domain and private sphere, and women are restricted within the private realm [5]. In Joan Tronto's point of view, the division between public and private life is a citadel of moral boundary, deriving from the traditional cultures and social contexts, which needs to be changed now.

In the late eighteenth century, the account of care started collapsing because it used to exist in the romantic families, and its attendant moral and political orders were built upon the assumption that men would venture out into a commercial world while women would take charge of the domestic. However, during the following eras in western industrial societies, functions of care have increasingly fallen into the purview of the state, and caring functions have also been moved into the market. The result is that the separation of public and private life that might have served as an ideological description of life in the nineteenth century can no longer be sustained. The separation of household and economic life no more describes the reality. And large part of the domestic activities that were previously private, such as caring for children, tending the ill, preparing meals and clothing, etc., has now been absorbed into social and market spheres. With these changed circumstances, the political and moral underpinnings that accompanied the gendered division of labor have also been eroded [5].

Following with the collapse of this boundary, the "traditional family" based on male bread-winning and female childrearing should also disappear from our current society, which means both spouses, working full-time in the paid labor force, should equally share housekeeping and childrearing tasks and other domestic labor. Otherwise, as so often happens, one spouse, almost always the wife, will end up with a second shift at home, which usually has detrimental effects on that spouse's work and well-being both inside and outside the family [6]. The meaning of breaking up the moral boundary between private and public domains extends to women's performance in politics. Liberating women from the overburden of domestic labor leaves more aspiration and energy for women to participate in public issues, which can elevate their status as a union and transform the attitude towards women's proper roles both in the family and society at large [7].

\subsection{Reconstruction of De-gendered Care}

As Joan Tronto worries, the caring is practiced in contemporary society through a gendered lens: In our usual sense of the term, "care" is seen as women's work [5]. The current constructions of masculinity and femininity permit men to avoid having to take, or to think much about, the responsibilities for the caring tasks assigned to women. The proportion of household labor undertaken by women is greatly higher than men. Mothering is a distinctly cultural activity, involving language and culture, that forms human social personhood and develops morality for all of us who were once children [8]. Individuals of both sexes, however, can be a mothering person who protects, nurtures, and trains a child Possibly fathers could come to be as emotionally close, or as close through caretaking, to children as mothers are. Persons, whether biological mothers or not, are encouraged to care for growing children, especially by forming families. An ideal family according to care ethics would, then, be first and foremost one in which spouses of both sexes share equally their primary responsibility to "mother" their children, whatever other functions they may perform outside of the family. And as it proved by Joan Tronto, men do care in the form of protection and production, but this still should not be their excuse of avoiding domestic labor [5]. Equal spouses should have the same responsibilities to share the burden of care used to be overtaken by the female in family.

The care work must be de-gendered, in fact, not in name only, which requires public programs of educating for dependency work, especially among young boys and men [9]. Just like the suggestion of James P. Sterba: Sometimes it is argued that men lack the necessary housekeeping or childrearing skills owning to a deficient upbringing in which they were taught that housekeeping and childrearing are not appropriate activities for men to undertake. But surely what this calls for is not the rejection of the standard of equal opportunity but rather the introduction of certain remedial programs to increase men's skills in this regard, in other works, affirmative actions for men. This also reflects the problems in the early education of girls and boys that, certain roles and jobs should not be open to them because of their sex, which will surely make it more difficult to create and maintain equal opportunity or fairness between women and men later in life. Within 
family girls and boys must be equally given the same type of upbringing consistent with their native capabilities rather than gender[6]. With the reconstruction of degendered care, the masculine nature of citizenship can also be challenged, and men are equipped and accustomed to dealing with the domestic labor of care, which provides a new complete political identity without gender stereotype on women to participate in public issues and men to take care of family.

The ethics of care strengthen to implement care without the boundary of public and private life. Meanwhile, the ethics of care demonstrate the reasons of sharing the commitment of care equally between men and women through dismissing the stereotype of gendered care. The way it can contribute to revise the sexist thoughts in Confucianism needs further deliberation based on the clarification of how Confucianism cultivates gender ideas and its remaining tremendous influence over the life of contemporary Chinese people.

\section{CONFUCIANISM: SEXIST IDEAS AND GENDERED CARE}

\subsection{Yin-Yang Sexual Hierarchy and Nei-Wai Gendered Labor Division}

Confucianism is the way of life propagated by Confucius in the 6th-5th century BC and followed by the Chinese people for more than two millennia. Although transformed over time, it is still the substance of learning, the source of values, and the social code of Chinese society. It spreads to other East Asian countries under the influence of Chinese literate culture and has exerted a profound influence on their spiritual and political life. Both the theory and practice of Confucianism have indelibly marked the patterns of government, society, education, and family of East Asia. Despite its fundamental role of Confucianism in cultivating the moral views for Chinese people, Confucianism can hardly absolve itself from the criticism of patriarchal and hierarchical views on care and its negative influence on the division pattern of care labor in its later eras [10].

The idea of Confucianist sexism is embodied into two dimensions, namely, the Yin-Yang thought and the NeiWei system. To be brief, women were thought to be subordinated and inferior to men because their nature was identified with Yin, which was lower and dependent on Yang as men's symbol. Meanwhile, women and men were obliged to different duties and ceremonies in divided spaces, Nei (within home) for women and Wai (out of home) for men. Under these two regulations of Yin-Yang and Nei-Wai, the pattern of labor division according to Confucianism was that women take care of domestic tasks, while men work outside.

Specifically, the sexual hierarchy initiated from the thought of Yin and Yang. Yin and Yang were two kinds of gases, and they were different with, meanwhile, dependent on each other. Their movements created and governed the universe. As a Chinese original cosmology, the system of Yin and Yang referred to two different sides of things, such as earth and heaven, warmth and cold, female and male, women and men; What needs to be mentioned is that in the primary Yin-Yang theory the qualitative differences, taking the differences between lights and shade as an example, were only relative and neutral [11]. However, after Han Dynasty the Yin-Yang theory transferred to a kind of hierarchic and gender-based system. The Yin and the Yang were explicitly correlated with a hierarchical scheme where the categories like heaven and men were privileged over earth and women. Dong Zhongshu, as the heirs of the thoughts of Confucian, enhanced the analogy between Yin-Yang thought and gender hierarchy: "Yang venerable, Yin humble" [12]. Fathers and husbands were regulated by Yang, while mothers and wives by Yin. Fathers and husbands were venerable, and mothers and wives were comparatively humble. After Han Dynasty, the notions of hierarchical Yin-Yang and its analogy that women were inferior to men were the mainstream in Confucianist thought, which was explicitly applied in the moral manuals to regulate women's behaviors. The system of Li (ceremonies) was developed simultaneously by the Confucians who governed the ideology of ancient Chinese. The application of $\mathrm{Li}$ set up the spatial segregation to restrain women in Nei and assigns the domestic labor to them, including weaving, spinning, embroidering, and food preparation for sacrificial ceremonies. The physical segregation between men and women led to the absolute seclusion of women within the inner quarters, and the ceremonies controlling women's behaviors gradually became stricter and more masculism.

To sum up, in the whole Chinese culture until 19th century, the relationship between women and men was regulated by the disciplines that women were different from and inferior to men. Meanwhile, women were obliged to respond for the care labor in family with obeying the ceremonial rites and spatial seclusion. These regulations set up by Confucianism ultimately exacerbate the problem of gender disparity in premodern China.

\subsection{The Continuous Influence of Confucian Sexism in the Case of Domestic Labor Division}

As the mainstay of Chinese culture, the orthodoxy of the ritual boundary and the construction of gendered care labor remain unchallenged until the Qing period (BC 1644-BC1912) [11]. In fact, the investigations and discussions in recent decades about the situation of unfair division of domestic care labor, to some extent, have illustrated the remnant influence of Confucian sexism in modern Chinese society.

According to three national surveys on the status of Chinese women conducted in 1990, 2000, and 2010, the pattern of female-dominated housework remained unchanged [13]. More than $85 \%$ of household chores, such as cooking, washing dishes, washing clothes, 
cleaning and sanitation, have been mainly undertaken by wives when both men and women have their own jobs. Although the gap of duration of housework between men and women becomes narrower, it is still difficult for women to relieve from the overburden of domestic labor [14]. (Chart 1)

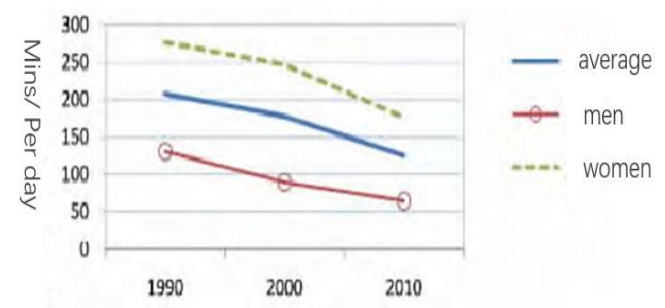

Chart 1. Daily Housework Duration of Men and Women in China from 1990 to 2010

Apart from analysing the pattern of housework division, the three national surveys also investigated the gender notions among Chinese people. According to the survey in 2010, over half of participants, including male and female, agreed that women's attention should mainly focus on family, while men act as the bread winner. Meanwhile, over 40 percent men and 48 percent women regarded marriage with a capable man as a better way to obtain a satisfactory life, compared with hard working by women themselves. (Chart 2)

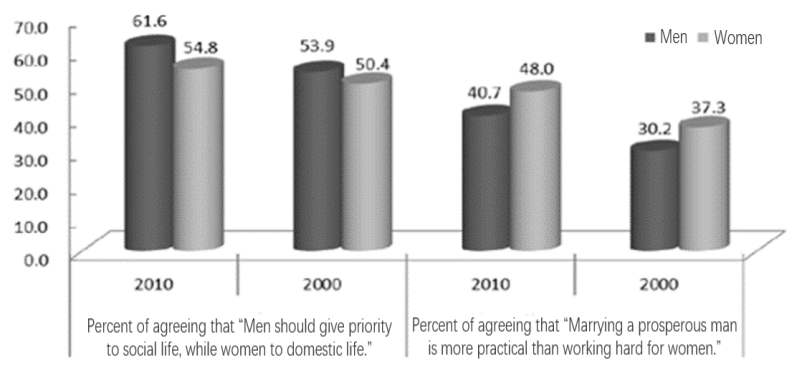

Chart 2. Gender Attitudes of Chinese Men and Women in 2010 and 2000

What's the women's attitudes toward the current pattern of housework division? As a survey held in Shanghai, exploring women and men's assessment of the division, shows that the amount of housework is the most influential element which affects the wife's evaluation of fairness in Chinese family [15]. The average score of urban married women's satisfaction with the division of housework is 3.2 , lower than that of men's 3.34; the satisfaction of suburban men with the division of housework is lower than that of urban men, and suburban women were more dissatisfied with the division of housework, which could result from the fact that suburban men are more in agreement with traditional gender roles. (Chart 3)

\begin{tabular}{lccc}
\hline & Urban Area & Suburban Area & Citywide Area \\
\hline Men & 3.35 & 3.28 & 3.34 \\
Women & 3.20 & 3.19 & 3.20 \\
Average & 3.28 & 3.23 & 3.27 \\
F-test & $36.80 \cdots$ & $12.75 \cdots$ & $50.37^{\cdots}$ \\
\hline
\end{tabular}

Chart 3. Variance Analysis on the Satisfaction of Housework Division

Based on existing data, it can be concluded that the idea of labor division based on the stereotypes of gender roles and the hierarchical relation between men and women stemming from the Confucianism still hinder the process of gender equality in contemporary China.

Apart from the nationwide surveys, there are also a series of newspapers reported that the public attitudes towards the fathers who deal with the domestic chores, including rearing babies, doing the cleaning labor, and cooking, are not positive. And it is highly possible to regard those men who take care of domestic labors as unsuccessful at their career or being controlled by wives due to their inability [16], which increases the reluctance for men to undertake the domestic labor indirectly.

The journalists criticized this kind of attitudes as a remnant of hegemonic masculinity [17]. This gender-based disparity of housework division has invoked many discussions in recent decades among scholars. Based on the data collection and interviews, scholars have been exploring the reasons of this unfair phenomenon in different contexts, which include the lagging laws and state policies failing to provide sufficient support for the welfare of women [18], and the competition in market exposing women who used to take care of families into a disadvantaged position [19]. In addition to the political and economic reasons, it is inevitable to think over the effect of the stereotypically gender-based division of labor in Confucianism. A number of researchers concentrate on the relationship between Confucianist thoughts about gender roles and the disparity of domestic labor. Chinese feminist scholars, like Xiao Wei [20] and Zhang Nian [21], they point out that the sexist construction of gender ideas in Confucianism underpins the suppression and constraint on women through the hierarchical and patriarchal notions about gender, which is inherent in the hierarchy of YinYang and the segregation of Nei-Wai in Confucianism. With exploring the embodiment of sexist thoughts in Confucianism, they are also eager to find suggestions to this chronic problem. Some of the scholars claim that solutions should be found within the context of Confucianism [22], while others try to criticize and revise it by referring to western feminist theories [23]. 


\section{REFLECTIONS ON THE CONFUCIANISM IN THE CRITICAL LENS OF CARE ETHICS}

Based on the comparative analysis of the relationship between care and gender as well as the moral boundary of private and public life, we could notice the internal tension between feminist care ethics and Confucianism. However, this analysis should not be ended up with the complete negation and eradication of Confucianism only out of its sexist thoughts, which might be neither rational nor possible since Confucianism is the origination and pillar of Chinese culture. At this point, the ethics of care could act as a critical lens to reflect the Confucian sexism and shed light on its revision and reconstruction of the relationship between gender and care in Confucianism. This modification could provide a foundation to develop Confucianism further by chasing the gloom of sexism and enrich the ethics of care in Sinitic background varying from its western contexts.

What should be under notice for the comparison is that both Confucianism and the ethics of care emphasize the importance of care. Nevertheless, just as part of the feminists in ethics of care have demonstrated that care should not be gendered. In contrast, Confucianism divides care into masculine care and feminine care. Men's care manifests as virtues like Jen, which is the core character of saints and promotes them to occupy official posts. On the contrary, the care related to women embodies in practical domestic labor, which has been regarded as an expression of women's maternal nature and undervalued in Confucianism. Referring to the critical analysis from the ethics of care, it is now high time to break free from the boundaries between the public and private spheres as well as the stereotypical relationship between care and gender. As Joan Tronto mentions in Moral Boundaries by citing Barrington Moore that people only perceive injustice when they recognize that social institutions are not natural but artificial. Change occurs when people recognize that their predicament has been created by human action and, therefore, the situation can be changed [5]. The moral boundaries of private and public domains rely on the ideological description of life in the eighteenth and nineteenth century, which can no longer be sustained now. And with the collapse of the separation of public and private life, the traditional family based on male breadwinning and female childrearing should be reflected as well. Meanwhile, the importance of care work in family should be revalued. Under these considerations, the problem of gender disparity of caring labor deriving from the Confucianist Yin-Yang and Nei-Wai systems should be reflected, and its hierarchical gender ideology should be rectified.

Once the gender stereotypes in Confucianism are taken away from the relation between husband and wife, what is remained is a more flexible rearrangement of the labor division in family. With this eradication of Confucian sexism, women will no longer be confined to the realm of Nei. This liberation hence would also guarantee women's equal access to pursuing the highest Confucianist ideal of becoming Junzi (a virtuous person) and ask for their social rights as a whole moral subject instead of as someone's mother, daughter or wife.

Apart from challenging the moral boundaries, which hinder the process of gender equality, Joan Tronto also emphasizes the importance of taking women into account of being cared, as well as, reallocating the assignment of domestic labor among women and men in reconstructing a caring democratic society. No one automatically receives a pass out of caring for themselves or others because they are involved in protection, production, or taking care of their own, or are sufficiently wealthy to lift themselves by their own bootstraps or to give to charity. Everyone, from the richest to the poorest, from the most self-reliant to the most dependent, from the woman used to be marginalized to the man dominant, has to sit down at the table and be involved in the renegotiation of caring responsibilities. The starting consideration of this renegotiation is that a truly equal society gives each person equal chances to be well cared for, to engage in caring relationships [5]. To rectify the Confucianist sexism, we need to figure out who is involved in making decisions and who is exercising various forms of privileged irresponsibility on the one hand, and who has been deprived of their basic rights of being heard and being cared on the other hand [24]. Including all parties in the negotiation of reallocating caring responsibilities could minimize the risk that paternalistic and parochial ideas prevail without reflections and challenges.

\section{CONCLUSION}

The ethics of care's reflections on the moral boundaries, namely the moral boundary between private and public life and the boundary between care and gender due to hegemonic masculinity, provide a critical lens to analyse and revise the sexist thoughts in Confucianism. By resorting to the two principles, namely, to include everyone in the framework of care and to reallocate the responsibility of care equally at the same time, the ethics of care shed a light on the method to rectify the Confucianist gender hierarchy and the disparity in domestic labor division, which contributes to relieve women from the overcommitment of care labor.

Reflecting and revising the sexist thoughts in Confucianism with the critical perspective of care ethics could be regarded as a possible response to the feminist challenge lying ahead for Confucianism. It is not simply only keeping Confucianism alive in the twenty-first century, but also an affirmation of the dynamic nature of Confucianism. Last but not least, the difficulties that whether such a rectification can be justified by the Confucianism itself and how to revise the Confucian sexism in theory and in practice specifically need more clarifications, and related questions are still open to more prudential discussions. 
Scientific Journal of Chinese Population, vol.3, 2003, pp. 43.

[16] Liu Aiyu, Men who do housework: Expression of emotion, economic dependence and gender equality attitude, Collection of Women's Studies, vol.3, 2015, pp.20.

[17] Zhang Xiaona, Study on the connotation of 'househusband' from the angle of etymology, Technological Science, vol.8, 2011, pp.565.

[3] Yuan Lijun, Ethics of care and concept of Jen: A reply to Chenyang Li, Hypatia. vol.17, 2002, pp. 107129.

[4] Ranjoo Seodu Herr, Confucian family for a feminist future, Asian Philosophy, vol.22, 2012, pp. 327-346.

[5] Joan Tronto, Moral Boundaries: A Political Argument for an Ethic of Care, Routledge Press, 1994.

[6] Sterba, P. James, Ethics: The Big Questions, Blackwell Publishing, 2009.

[7] Elizabeth K. Markovits and Susan Bickford, Constructing freedom: Institutional pathways to changing the gender division of labor, Perspectives on Politics, vol. 12, pp. 81-99.

[8] Held, Virginia, The Ethics of Care: Personal, Political, Global. Oxford University Press, 2006, pp5556.

[9] Eva Feder Kittey, Love's Labor: Essays on Women, Equality and Dependency, Routledge Press, 1999, pp.143.

[10] Xiao Wei, An analysis of Confucian traditional ideas and modern concepts of equality between men and women, China Women's Daily, vol. 1,2017.

[11] Li-Shiang Lisa Rosenlee, Confucianism and Women: A Philosophical Interpretation, State University of New York Press, 2006, pp.63-75.

[12] Dong Zhongshu, Chunqiu Fanlu, Shanghai Masterpiece Press, 1989.

[13] National Bureau of Statistics, The Third Report on the Survey of Social Status of Women in China, 2010.

[14] Yang Juhua, Continuity and strategy: A gender pattern of household work division in China from 1990 to 2010, Academic Research Journal, vol.2, 2014, pp. 34.

[15] Xu, Anqi, The division of housework and its unfairness, based on the experience of Shanghai,
[18] Wu Fan, Women's status in family and society, based on the analysis of their resources and characters, Academic Study, vol.1, 2014, pp.42.

[19] Wu Xiaoying, The transformation of gender discourse in the context of marketization, Chinese Social Science, vol.2,2009, pp.164.

[20] Xiao Wei, Traditional Confucian thought and modern notion of gender equality, Journal of Chinese Women, vol. 1,2017, pp.1.

[21] Zhang Nian, Gender Politics and State: On Women's Liberation in China, The Commercial Press, Beijing, 2015.

[22] Xiao Wei, Gender equality: The task of developing Confucianism in the modern and global context, Chuanshan Journal, vol.1, 2018, pp.9.

[23] Peng Hua, Study on the method of transforming the thought of gender role in Confucianism, Studies in Ethics, vol.2, 2014, pp.98.

[24] Joan C. Tronto, Caring Democracy: Markets, Equality, and Justice, New York University, 2013, pp.63-64. 